\title{
Corrigendum: Long-term survival in a child with severe encephalopathy, multiple respiratory chain deficiency and GFM1 mutations
}

\author{
Sara Brito ${ }^{1,2 *}$, Kyle Thompson ${ }^{3}$, Jaume Campistol ${ }^{2,4}$, Jaime Colomer ${ }^{2}$, \\ Steven A. Hardy ${ }^{3}$, Langping He ${ }^{3}$, Ana Fernández-Marmiesse ${ }^{5}$, Lourdes Palacios ${ }^{6}$, \\ Cristina Jou ${ }^{7}$, Cecilia Jiménez-Mallebrera ${ }^{2,4}$, Judith Armstrong ${ }^{4,8}$, Raquel Montero ${ }^{4,9}$, \\ Rafael Artuch ${ }^{4,9}$, Christin Tischner ${ }^{10}$, Tina Wenz ${ }^{10,11}$, Robert McFarland ${ }^{3}$ and \\ Robert W. Taylor ${ }^{3}$
}

${ }^{1}$ Serviço de Pediatria, Centro Hospitalar de Leiria, Hospital de Santo André, Leiria, Portugal, ${ }^{2}$ Neuromuscular Unit, Neuropaediatrics Department, Hospital Sant Joan de Déu, Barcelona, Spain, ${ }^{3}$ Wellcome Trust Centre for Mitochondrial Research, Institute of Neuroscience, Newcastle University, Newcastle upon Tyne, UK, ${ }^{4}$ Centro de Investigación Biomédica en Red de Enfermedades Raras, Instituto de Salud Carlos III, Barcelona, Spain, ${ }^{5}$ Diagnosis and Treatment Unit for Inborn Errors of Metabolism, Hospital Clínico Universitario de Santiago de Compostela, La Coruña, Spain, ${ }^{6}$ Progenika Biopharma a Grifols Company, Derio, Spain, ${ }^{7}$ Pathology Department, Hospital Sant Joan de Déu, Esplugues Barcelona, Spain,

${ }^{8}$ Biochemical, Genetics and Rett Unit, Laboratory Department, Hospital Sant Joan de Déu, Esplugues Barcelona, Spain, ${ }^{9}$ Biochemical Department, Hospital Sant Joan de Déu, Esplugues Barcelona, Spain, ${ }^{10}$ Cluster of Excellence, Cellular Stress Responses in Aging-Associated Diseases, Institute for Genetics, University of Cologne, Cologne, Germany, ${ }^{11}$ German Network for Mitochondrial Disorders, Munich, Germany

Keywords: GFM1, mtEFG1, mitochondrial disorders, brain MRI, encephalopathy

\section{OPEN ACCESS}

Edited and reviewed by: David B. Allison, University of Alabama at Birmingham,

*Correspondence: Sara Brito, sarabri@gmail.com

Specialty section: This article was submitted to Genetic Disorders, a section of the journal Frontiers in Genetics

Received: 16 June 2015 Accepted: 13 July 2015 Published: 28 July 2015

Citation:

Brito S, Thompson K, Campistol J, Colomer J, Hardy SA, He L, Fernández-Marmiesse A, Palacios L, Jou $C$, Jiménez-Mallebrera $C$ Armstrong J, Montero R, Artuch R, Tischner C, Wenz T, McFarland R and Taylor RW (2015) Corrigendum: Long-term survival in a child with severe encephalopathy, multiple respiratory chain deficiency and GFM1 mutations. Front. Genet. 6:254. doi: 10.3389/fgene.2015.00254

\section{A corrigendum on}

Long-term survival in a child with severe encephalopathy, multiple respiratory chain deficiency and GFM1 mutations

by Brito, S., Thompson, K., Campistol, J., Colomer, J., Hardy, S. A., He, L., et al. (2015). Front. Genet. 6:102. doi: 10.3389/fgene.2015.00102

In our article entitled, "Long-term survival in a child with severe encephalopathy, multiple respiratory chain deficiency and GFM1 mutations," published in Frontiers in Genetics on 23rd March 2015 we inadvertently omitted information that the attending paediatrician believes may be relevant to the case. In the interests of accuracy and completeness we would like to add that the patient we describe had been receiving treatment with Ubiquinone $(20 \mathrm{mg} /$ day), Riboflavin (100 $\mathrm{mg}$ /day), Carnitine (500 mg/day), $\mathrm{N}$-acetylcysteine (100 mg/day), and Folinic acid (15 mg/day) for 6 months prior to inclusion in the report. While there was no obvious improvement in her condition, equally she has not exhibited any further clinical deterioration since treatment began. Radiological progression was, however, evident on a cranial MRI performed 5 months after treatment was initiated. Given the relatively short duration of treatment (approximately 6 months at the time of writing the report) and the neuroradiological progression evident on the repeat cranial MRI, we consider it unlikely that this vitamin and antioxidant treatment has made a substantial contribution to the patient's longer survival.

Conflict of Interest Statement: The authors declare that the research was conducted in the absence of any commercial or financial relationships that could be construed as a potential conflict of interest.

Copyright $\odot 2015$ Brito, Thompson, Campistol, Colomer, Hardy, He, Fernández-Marmiesse, Palacios, Jou, Jiménez-Mallebrera, Armstrong, Montero, Artuch, Tischner, Wenz, McFarland and Taylor. This is an open-access article distributed under the terms of the Creative Commons Attribution License (CC BY). The use, distribution or reproduction in other forums is permitted, provided the original author(s) or licensor are credited and that the original publication in this journal is cited, in accordance with accepted academic practice. No use, distribution or reproduction is permitted which does not comply with these terms. 